\title{
Perra en celo de un sueño rojo: de la revolución al devenir. Reflexiones desde una práctica estética sobre la posibilidad del sujeto y la política contemporáneas*
}

Fecha de recepción: 11 de noviembre de 2017

Fecha de aprobación: 13 de febrero de 2018

\section{Resumen}

Preguntarse por el problema de la política en la teoría social contemporánea, nos enfrenta a la tensión que se presenta en la articulación entre la acción política capaz de transformar lo social y la disolución del sujeto. Si no hay sujeto, tampoco autores, ni personalidades, ni líderes en el sentido moderno de estos términos, ¿cuáles son las modalidades de acción social y política capaces transformar el curso de la historia? A partir de esta pregunta, y sirviéndonos de la noción de políticas del ano de Paul B. Preciado, tomaremos la teoría y las prácticas queer para ahondar en la relación entre procesos micro y macropolíticos, enfocando en los modos de producción subjetiva y los procesos de creación artístico-cultural capaces de trastocar los límites de lo posible. Así, Susy Shock, como un caso de militancia artística con manifiesto arraigo político queer de la escena under de Buenos Aires, nos permitirá acceder al análisis de un proceso de producción estético-político-teórico.

Palabras clave: sujeto; subjetividad; multitud; políticas del ano; cambio social; artivismo; disidencia sexual.

Citar: Luzza Rodríguez, P. G. (enero-junio de 2018). Perra en celo de un sueño rojo: de la revolución al devenir. Reflexiones desde una práctica estética sobre la posibilidad del sujeto y la política contemporáneas. La Palabra, (32), 139-154. doi: https://doi.org/10.19053/01218530.n32.2018.8170.

\section{Pablo Gabriel Luzza Rodríguez}

Docente del Instituto Universitario de la Policía Federal. Maestrando en Estudios Interdisciplinarios de la Subjetividad, de la Facultad de Filosofía y Letras de la Universidad de Buenos Aires y Becario Doctor del Consejo Nacional de Investigaciones Científicas y Técnicas. Editor Responsable de Diferencia(s), Revista de Teoría Social Contemporánea. pablo.luzza@gmail.com

*Artículo de reflexión. 


\section{la palabra}

\section{Bitch in Heat of a Red Dream: from Revolution to Becoming. Reflections from a Practical Aesthetics on the Possibility of a Contemporary Subject and Politics}

\section{Abstract}

The problem of politics in contemporary social theory confronts us with the tension between political action capable of social transformation, and the dissolution of the subject. If there is neither subject, nor authors, personalities or leaders, in the modern conception of these terms, what sort of social and political actions would be able to change the course of history? Considering the notion of 'anal politics' proposed by Paul B. Preciado, this article concentrates its analysis on queer theories and practices, in order to offer a possible reading of the relation between micro and macropolitical processes and their implication on the production of subjects, as well as artistic and cultural creativity. The Argentinian artivist poet Susy Shock, of manifest queer political rooting, will serve as a case study to inquire into an aesthetic-political-theorical process that challenges the social frontiers of the possible.

Keywords: Subject; Subjectivity; Multitude; Anal politics; Social change; Artivism; Sexual dissidence.

Perra en celo de un sueño rojo: de la revolución al devenir [Chienne en chaleur d'un rêve rouge: de la révolution au devenir] Réflexions à partir d'une pratique esthétique sur la possibilité du sujet et de la politique contemporaines.

\section{Résumé}

S'interroger sur la question du politique dans la théorie sociale contemporaine nous met face à la tension qui apparaît dans l'articulation entre l'action politique capable de transformer l'espace social et la dissolution du sujet. S'il n'y a plus de sujet, il n'y a plus d'auteur, ni de personnalités, ni de dirigents au sens moderne de ces termes. Quelles sont les modalités de l'action sociale et politique capables de transformer le cours de l'histoire? À partir de cette question, nous utiliserons le concept de politique de 
l'anus de Paul B. Preciado ainsi que la théorie et les pratiques queer pour examiner la relation entre les processus micro et macropolitiques. Nous nous concentrerons sur les modes de production de la subjectivité et les processus de création artistique et culturelle capables de bouleverser les limites du possible. De cette manière, Susy Shock, en tant qu'exemple de militantisme artistique de tendance politique queer de la scène indépendante de Buenos Aires, nous permettra d'analyser le processus de production esthétique, politico-théorique.

Mots-clés: sujet; subjectivité; foule; politique de l'anus; changement social; artivisme; dissidence sexuelle

\section{¿Un sujeto postestructuralis- ta? $O$ ¿quién alzará las ban- deras de la revolución?}

El posestructuralismo fuerza los límites del estructuralismo antecesor que había llegado a proponer la homología entre sociedad y orden simbólico, para concentrarse en el campo de la discursividad como productor de ese orden y sistema de diferencias. Esto permite al posestructuralismo, en línea con el antihumanismo estructuralista, sostener la desaparición del sujeto, la autonomía del discurso, y la interpretación de la cultura como sistema de signos (Noguera, 2003).

Puede identificarse en esta corriente, un abandono de la caracterización clásica del sujeto constituyente cartesiano. $\mathrm{Su}$ carácter racional, libre y monádico, y su posición como productor último de lo social, son entendidos como una ficción alienante, "[...] operador clave de una cultura racional-cientificista y de un orden social capitalista que procuran el do- minio total de los individuos y de la naturaleza." (Tonkonoff, 2009, p. 2). El posestructuralismo considera al sujeto descentrado, abierto, constituido por los juegos del lenguaje y del deseo, permanentemente "en proceso". El postulado del "yo" como ficción del lenguaje, no remite simplemente a la idea de que el sujeto sea una construcción histórico-social, sino lisa y llanamente una construcción discursiva, ligada a la idea del discurso como productor de los sentidos, la realidad, el mundo. Se trata de una filosofía radicalmente anti-cartesiana $\mathrm{y}$ anti-hobbesiana, que buscar ir más allá de la reducción de lo político y del sujeto a la unidad, a la mónada; pero también podría entenderse como pos-kantiana en tanto que el apriori del sujeto deja de ser metafísico, pasa a ser pensado como "[...] el artificio, o la ficción (fabricación, elaboración) que lo produce. [...] Un apriori donde se agencian las multiplicidades [...]. Un apriori que, más allá de las filosofías de lo Uno, afirma la agencia de la multiplicidad y el carácter resistente de las singularidades [...].” (Fernández de Rota, 2008, p. 68).

Tal concepción del sujeto da lugar a dos aporías y a dos estrategias políticas. La primera, de carácter lingüístico, atañe al problema de sostener al lenguaje como el sujeto constituyente, lo cual, al reducir al agente a mera posición de sujeto, parecería impedir toda concepción de historia y política, siendo el lenguaje el sujeto autónomo. La segunda aporía es la que lleva a absolutizar los momentos liminares y de ruptura, concentrando el interés en la locura, la irracionalidad, la transgresión, la violencia, lo "otro" de la razón y la subjetividad, lo cual nos dejaría sin construcción posible, sin "realidad" compartible ni disputable.

A la primera aporía corresponde, como estrategia política, ligar la subjetividad a "lo otro" del sujeto, a lo "imposible". Permitir la aparición de lo nuevo, poniendo al sujeto "en proceso", dejando emerger en el 
lenguaje lo que lo excede, lo que el significante no marca ni domina. A la segunda corresponde una nueva objetivación del sujeto y el cuerpo social, dando lugar a nuevas formas de subjetividad, asumiendo el potencial creativo de "lo otro". Lo que políticamente parece estar en juego y que pone en el centro el problema de la (im) posibilidad del sujeto, es lo que define el límite de lo social, constituyendo un exterior que lo amenaza y lo hace posible al mismo tiempo. Despunta aquí el cariz político de la perspectiva posestructuralista que nos interesa: reconocer la potencia del deseo y las estrategias de agenciamiento $^{1}$ del mismo, la tensión entre sobrecodificación y mutación, entre revoluciones moleculares y luchas de interés, entre norma y parodia.

Ahora bien -y a riesgo de errar la pregunta y reproducir posiciones o estructuras lógicas que exceden a esta perspectiva-con un sujeto escindido de esta manera, y concebido como producto de agenciamientos y dispositivos ¿quién puede disputar el campo social? ¿qué valor tienen las experiencias subjetivas individuales si es que puede seguir sosteniéndose su existencia? ¿dónde quedan y cómo existen los cuerpos dotados de conciencia que soportan y forman parte de esos agenciamientos y dispositivos?

A partir de estas preguntas, el presente trabajo ofrecerá un análisis que, partiendo de "un sujeto y su obra", intentará ofrecer una mirada sobre las instancias liminares entre lo individual y lo colectivo, y sobre los modos de subjetivación contemporáneos en los que se disputa el orden establecido a través de estrategias y discursos colectivos en torno del género y la disidencia sexual. Susy Shock - poeta, actriz, cantautora $\mathrm{y}$ activista argentina- oficiará de tal "sujeto" capaz de introducirnos en los procesos de singularización de la disidencia sexual -tomada como colectivo- y en las políticas del ano capaces de disputar a través de la cultura como foro de creación, los límites de lo social.

\section{Capitalismo contemporáneo: economía subjetiva y micro- política}

Guattari y Rolnik (2006) nos permiten una aproximación al problema del sujeto contemporáneo, partiendo de la descripción de lo que denominan Capitalismo Mundial Integrado
(CMI) como diagrama, como sistema general de semiotización que inscribe el campo social, que lo cartografía, poniendo en relación distintas máquinas a fin de extraerles plusvalor maquínico. El CMI produce los modos de las relaciones humanas, siendo el sujeto en este territorio específico, un agenciamiento colectivo de enunciación producto de procesos de semiotización no individuales y no grupales, doblemente descentrados en relación al individuo. Los procesos de semiotización se encuentran doblemente descentrados en tanto que efecto de la superposición de máquinas "extrapersonales" (sistemas económicos, tecnológicos, icónicos, ecológicos, mediáticos) e "infrapersonales" (sistemas de percepción, sensibilidad, afecto, deseo, representación, biológicos, fisiológicos, etc.). Frente al individuo dotado de un ego con pretensión de continuidad y poder, la subjetividad se constituye como fabricada en el registro de lo social y no totalizable en una única figura como la del individuo. El individuo es, para Guattari, una terminal consumidora de subjetividad, siendo el yo, el superyó, el reconocimiento en un cuerpo o en un sistema de pertenencia, momentos de individuación de

\footnotetext{
El término agenciamiento refiere a los modos en que el deseo es segmentado, semiotizado. Aquello que está suelto, disponible, es apropiado en "algún sentido" en relación a otros elementos, es integrado como parte de una estructura. Todo agenciamiento acarrea componentes heterogéneos: biológicos, sociales, maquínicos, gnoseológicos. El agenciamiento es la acción que desempeñan, en el modelo de Deleuze y Guattari, las máquinas abstractas, ya se trate de las de sobrecodificación o de las de mutación; agenciando los flujos de deseos y creencias por medio de agenciamientos concretos -que pueden denominarse también dispositivos- dan lugar a nuevas líneas de potencialidad, sobrecodifican los segmentos semiotizándolos (Guattari, 2004).
} 
la subjetividad. Lo que interesa, entonces, es elucidar cómo los agenciamientos de enunciación conectan las instancias infra $y$ extra personales.

De lo que se trata es de una economía subjetiva, la cual se sirve de sistemas de identificación modelizantes que posibilitan, a través de la culpabilización, los procesos de individuación integrada y normalizada. Tales procesos pueden pensarse a nivel biológico (cuerpo, nutrición, supervivencia, etc.), a nivel de la división sexual (etiquetamiento que permita hacer al individuo referenciable) ${ }^{2}$ y a nivel de las relaciones socioeconómicas (clase social). Se entiende entonces que el individuo emerge de la encrucijada de múltiples componentes de subjetividad, y puede pensarse la posibilidad de la lucha política a nivel de la reapropiación de los medios de producción y expresión política que hacen a la economía subjetiva dentro del CMI. Esta lucha supone desafiar los procedimientos de culpabilización, resistiéndose a las exigencias de consistencia y co- herencia individuales del sujeto cartesiano. De lo que se trata es de lo que los autores denominan proceso de singularización, en tanto que reapropiación de los componentes de la subjetividad a través de una relación de expresión y creación, en oposición a los procesos de integración y normalización. Si las teorías críticas modernas apuntaban a la disputa política de la transformación social a nivel de la economía política, la crítica posmoderna y posestructuralista viene a señalar la dimensión subjetiva, ontológica.

Los procesos de singularización son devenires diferenciales ${ }^{3}$ que pueden pensarse como revoluciones moleculares, luchas relativas a las libertades, al deseo, a los cuestionamientos de la vida cotidiana. La revolución molecular es portadora de coeficientes de libertad inasimilables e irrecuperables por el sistema dominante; sin embargo, no es posible saber en qué dirección se desplazarán o qué posibilidades traerán los flujos moleculares. El "destino" de las revoluciones moleculares se resuelve en su capacidad de articularse con "luchas de interés; luchas "clásicas" por reivindicaciones económicas, sociales, sindicales, que remiten a elementos ya axiomatizados sobre los que se disputa el ejercicio del poder. Los procesos de singularización frustran los mecanismos de interiorización de los valores capitalistas, actuando en tres niveles: el infrapersonal, que atañe al nivel de los sueños y la creación; el personal, que remite a las relaciones de autodominación del superyó; y el interpersonal, que involucra las formas de sociabilidad. Esto permite a Guattari describir la singularización como un proceso automodelador, que capta los elementos de la situación y construye sus propias referencias prácticas y teóricas, sin permanecer en una posición de constante dependencia respecto del poder global. Se trata de estrategias micropolíticas, en tanto que intento de lograr agenciamientos que impidan que los procesos de singularización se neutralicen mutuamente o sean recuperados como identidades, potenciando a los agenciamien-

2 Al respecto, Butler sostiene que "[...] La matriz cultural -mediante la cual se ha hecho inteligible la identidad de géneroexige que algunos tipos de «identidades» no puedan «existir»: aquellas en las que el género no es consecuencia del sexo y otras en las que las prácticas del deseo no son «consecuencia» ni del sexo ni del género. [...] precisamente porque algunos tipos de «identidades de género» no se adaptan a esas reglas de inteligibilidad cultural, dichas identidades se manifiestan únicamente como defectos en el desarrollo o imposibilidades lógicas desde el interior de ese campo [...]." (Butler, 2007, pp. 72-73). Llevándolo a la terminología de Deleuze y Guattari, podemos entender la matriz heterosexual de inteligibilidad cultural, como una máquina abstracta de sobrecodificación que territorializa los flujos de las múltiples configuraciones posibles del deseo, segmentándolos de forma binaria.

3 "Expresión relativa a la economía del deseo. Los flujos de deseo proceden mediante afectos y devenires, con independencia del hecho de que puedan o no ser rebajados a personas, imágenes, identificaciones. De esta suerte, un individuo, antropológicamente etiquetado como masculino, puede estar atravesado por devenires múltiples y aparentemente contradictorios: un devenir femenino que coexiste con un devenir niño, un devenir animal, un devenir invisible, etc." (Guattari, 2004, pp. 133134). 
tos unos con otros, evitando su reificación.

Guattari llama la atención sobre el modo en que los devenires -devenir-negro, devenir-mujer, devenir-niño, devenir-loco, etc.- son captados por la axiomática de la discriminación subjetiva capitalista, la cual los encasilla inmediatamente en referencias afectivas y teóricas. Son estas instancias las que permiten observar con claridad la articulación entre el nivel molecular de la integración subjetiva y el de los problemas políticos y sociales más generales, el punto de encuentro entre las problemáticas del inconsciente y los problemas políticos en el cual se encuentran los procesos subjetivos que escapan a las identidades. Todo lo cual no supone más que asumir que las palabras, sistemas de intercambio $\mathrm{y}$ representaciones que pertenecen a todo el campo social se articulan de modos singulares en la existencia, en oposición al sometimiento de las singularidades a un único cuadro de referencia identificable. Esta articulación, desde la perspectiva adoptada, puede observarse en múltiples niveles, pero nos interesa particularmente aquí, rescatar lo que Félix Guattari denomina equipamientos colectivos. Estos consisten en máquinas de signos, modos colectivos de semiotización que permiten la organización de todo grupo humano, que antes de adquirir la forma de instituciones y dis- positivos, se implantan en el corazón de los modos de subjetivación y de praxis, conectando: máquinas deseantes moleculares, relaciones interpersonales molares (sexuales, de clase, de edad, etc.), relaciones económicas y formaciones de poder políticas y sociales.

Desde este punto de vista, la lengua dominante, fuertemente sintactizada y con ejes paradigmáticos sólidamente codificados, es la que impide el acceso a todas las semióticas particulares: artísticas, miméticas, somáticas, biológicas, musicales, etc. El lenguaje como equipamiento colectivo, funciona como un embridado que amarra el orden de las cosas al orden de los signos, asignando lugares en sus redes y ofreciendo ejes "normales" al pensamiento. Aquí es donde el método esquizoanalítico se propone indagar en los modos en que se produce la sumisión generalizada a las semiologías del lenguaje y los significantes dominantes, "captar el virus micropolítico" funcionando en las múltiples máquinas que nos conforman.

Diremos entonces con Guattari, que el individuo está enteramente fabricado por la sociedad, específicamente por sus equipamientos colectivos. No hay sujeto trascendental ni esencia del sujeto; no puede haber, por lo tanto, sujeto libre, autónomo, consciente capaz de liberarnos de la sujeción se- miótica, solo podemos intentar agenciamientos colectivos de enunciación singulares para resistir a tal sujeción y desviarla de sus fines capitalísiticos.

Así, teniendo en cuenta la particularidad de los devenires, cabe pensar en la centralidad de los movimientos sociales o los colectivos en el sostenimiento de procesos transversales de devenires subjetivos que atraviesen todas las estratificaciones, sin estratificarse ellos mismos. Movimientos pensados como máquinas de guerra, capaces de lograr agenciamientos de carácter siempre procesual en resistencia al reconocimiento y la identidad y con una posición ofensiva, movilizadora de devenires y no meramente defensiva.

Multitudes queer y políticas del ano: micropolítica de los anormales

En línea con la matriz que acabamos de presentar, Preciado hace una lectura política de los movimientos queer, insistiendo en la relación entre activismo y teoría. Sirviéndose del concepto de devenir homosexual, sostiene que entre fines de los 60 y fines de los 80 puede reconocerse en EE. UU. y Europa, la aparición de lo que denomina "políticas del ano". Estas consisten en agenciamientos colectivos frente a las bio/tanatopolíticas de gobierno de lo social; micropolíticas de maricas, lesbianas, travestis y transexuales que 
oponen a la política como guerra, una nueva política entendida como relación, fiesta, comunicación autoexperimentación $\mathrm{y}$ placer, por lo que pueden entenderse como contra-biopolíticas. Preciado las denomina "políticas del ano", en tanto que se trata de formas de acción y crítica que reaccionan contra las estrategias biopolíticas que inventan la desviación sexual y sus patologías a través de métodos médico-jurídicos, de las que hablara Foucault (2002). Se trata de "[...] políticas del cuerpo, redefiniciones de la especie humana y de sus modos de (re) producción $[\ldots]$ se trata $[\ldots]$ del cuerpo como plataforma relacional vulnerable, histórica y socialmente construida, cuyos límites se ven constantemente redefinidos." (Preciado, 2009, p. 148).

Preciado sostiene que este tipo de agenciamiento colectivo que coloca la vulnerabilidad del cuerpo y su supervivencia en el centro el discurso político, hace de la cultura un foro de creación en el que se definen los límites de lo socialmente posible; la cultura como arena en la que disputar los límites de lo social, y desde la que resistir a los sistemas de identificación modelizante por medio de revoluciones moleculares, lo cual pone en un lugar central a los medios de comunicación en tanto que vectores de producción del espacio público, como flujos no informativos, sino polémicos.

En el contexto de las políticas del ano, la homosexualidad, entendida como devenir, habla en nombre de todos; es, para Preciado, un modelo de resistencia y recodificación de los flujos de saber poder, que cuestiona todas las formas de producción deseante y supone la construcción de otra forma de conocimiento, otro sujeto de la enunciación científica ${ }^{4}$, despejando un nuevo campo epistemológico. La relación entre teoría queer y militancia, se presenta como la posibilidad de que esa "mayoría silenciosa", acallada, pueda producir un saber sobre sí misma, reapropiándose de las tecnologías de poder que los constituyeron como abyectos:

el cuerpo queer (ni masculino ni femenino, ni infantil ni adulto, ni humano ni animal) es aquel que se construye como sujeto que resiste y contesta a ese proceso de normalización pedagógica, encontrando puntos de fuga que permitan agenciamientos desviados. (Preciado, 2009, p. 168).

En un artículo posterior, Preciado se sirve del concepto de multitud $^{5}$ sosteniendo la necesidad de abandonar la idea de "diferencia sexual" en favor de la de "multitudes queer". Estas constituirían el cuerpo de la sexopolítica como una de las formas dominantes de la acción biopolítica del capitalismo contemporáneo, lo que podríamos entender como uno de esos elementos que articulan los agenciamientos de los que depende la subjetivación.

$4 \quad$ Podría indagarse en este punto a partir de la concepción de genealogías de Michel Foucault. Según Foucault, la posibilidad de criticar y resistir al discurso científico, se desprende del "retorno" de un conjunto de "saberes sometidos", de su "insurrección" (2002). Todo un conjunto de saberes eruditos, técnicos, pero también "saberes de la gente" descalificados por el discurso científico. Saberes de los psiquiatrizados, los enfermeros, los delincuentes. Se trata de todos aquellos enunciados y formaciones discursivas que forman parte del saber, pero que el discurso científico, en ejercicio de su poder, ha excluido. Se entiende entonces a las genealogías como el acoplamiento de los conocimientos eruditos y las memorias locales para oponer resistencia a los saberes englobadores, las vanguardias teóricas y los efectos centralizadores de la ciencia. Consisten en la utilización táctica de los saberes contra los saberes hegemónicos; son en este sentido "anticiencias".

5 Hardt y Negri (2002) forjan el concepto de multitud, con relación a su reflexión sobre el Imperio como el modo de soberanía mundial contemporánea, un aparato de mando descentrado y desterritorializado, con fronteras abiertas, que se maneja por medio de identidades híbridas y jerarquías. En el Imperio, la producción de riqueza se encuentra relacionada con la producción biopolítica, con la producción de la misma vida social en la cual se superponen lo económico, lo político y lo cultural. Este tipo de producción viabiliza a la multitud como "cuerpo biopolítico colectivo", multitud de cuerpos singulares que buscan relación: "[...] es, producción como reproducción, estructura y superestructura, porque es vida en el más pleno sentido y política en el sentido estricto." (p. 30). La multitud, liberada por el imperio, es el poder desterritorializador que actúa como fuerza productiva que lo sostiene y que hace posible su destrucción. El potencial de la multitud es ser auto-organización biopolítica. 
La sexopolítica forma parte de los cálculos del poder, el cual hace de los discursos sobre el sexo y de las tecnologías de normalización de las identidades sexuales, un agente de control sobre la vida. Sin embargo, Preciado toma los cuerpos y las identidades de los "anormales" como potencias políticas y rescata su capacidad de incidencia sobre los dispositivos biotecnológicos de producción de subjetividad sexual, en tanto que llevan en sí mismos, como fracaso o residuo, la historia de las tecnologías de normalización (Preciado, 2003). Con estas premisas, Preciado puede sostener que la sexopolítica no es solo un lugar y una prerrogativa del poder, sino también un espacio de creación en el que se yuxtaponen los movimientos feministas, homosexuales, transexuales, intersexuales, transgénero, postcoloniales, movilizando procesos de desterritorialización de la heterosexualidad con la transversalidad de los devenires que atraviesan desde el espacio urbano hasta los propios cuerpos.

Esta comprensión de la multitud queer, advierte el autor, debe evitar concebir a las multitudes queer como opuestas a las estrategias identitarias, punto en el cual podría señalarse cierta distancia respecto de lo planteado por Deleuze y Guattari (2002). Podremos, sin embargo, entender este acento, al observar las estrategias políticas de las mul- titudes queer reseñadas por el autor. Preciado considera como estrategias sexopolíticas: la desidentificación, como no reconocimiento en ninguna de las categorías disponibles; las identificaciones estratégicas, como identificaciones negativas, de gueto, híper o posidentitatrias, que dan lugar a la producción de identidades de resistencia; la reconversión de las tecnologías del cuerpo que reapropian los discursos médicos anatómicos y pornográficos, de los saberes/ poderes sobre el sexo para subvertirlos; y la desontologización del sujeto de la política sexual, en tanto que crítica radical del sujeto unitario del feminismo.

De este modo, Preciado articula, en términos más operativos, la consigna de montar máquinas de guerra capaces de lograr agenciamientos de carácter siempre procesual en resistencia al reconocimiento y la identidad con una posición ofensiva, movilizadora de devenires. Máquinas que solo pueden ponerse en funcionamiento desde los sujetos y con lo que los sujetos cuentan como portadores, en sus cuerpos, de las técnicas sexopolíticas que los han constituido como tales en el contexto del CMI. Si no hay sujeto de derecho, inteligible, por fuera de los parámetros identitarios, de los procedimientos de semiotización del deseo y su segmentación, jugar justamente con esos parámetros e inevitablemente desde esos paráme- tros, constituirá la táctica y la estrategia políticas.

Tomando lo propuesto por Butler (2002; 2007), de lo que se trata es de disputar la norma por medio de las brechas que abren en ella la necesidad de su repetición. Siendo que el género tiene un carácter performativo y que no consiste en una fabricación voluntaria, sino en una repetición obligatoria de normas anteriores -lo cual permite distinguir performatividad, la del género, de performance, la que el sujeto "pone en escena" deliberadamente- lo que debemos considerar es su inevitable teatralidad. Es esta teatralidad la que abre la posibilidad de su reapropiación paródica, sirviéndose de apelativos homofóbicos que marcan al sujeto como abyecto, no inteligible, citándolos, los sujetos queer imitan e hiperbolizan la convención discursiva que también invierten -una identificación estratégica-, dejando así, mediante un "gesto hiperbólico", expuesta la ley homofóbica;

[...] es imposible contraponer lo teatral a lo político en las políticas queer actuales: la performance hiperbólica [...], el outness teatral con el cual el activismo homosexual ha infringido la rígida distinción entre el espacio público $y$ el espacio privado, han hecho proliferar escenarios de politización y concienciación [...] (Butler, 2002, p. 10). 
Un sujeto postestructuralista: Susy Shock

Yo digo que soy un hecho artístico. Trato de no nombrarme. [...] dejar de nombrarnos y empezar a transitar todas las posibilidades de lo que somos. Susy es esa búsqueda. [...] cuando nuestra sexualidad permite investigar, meterse en los recovecos, uno se entera de que se pueden vivir otras realidades, adquirir otras personalidades. Uno se autogestiona lo que uno es (Tauil, 2009).

Se presenta así, quien intentaremos pensar como un "sujeto político contemporáneo", como un "sujeto del posestructuralismo", caricaturizando, como el "agente de la revolución molecular":

Yo, pobre mortal, equidistante de todo, yo DNI 20598061, yo primer hijo de la madre que después fui, amazona de mi deseo, perra en celo de mi sueño rojo, yo, reivindico mi derecho a ser un monstruo, ni varón, ni mujer, ni XXY, ni H2O. [...] Reivindico: mi derecho a ser un monstruo y que otros sean lo Normal. (Susy Shock, 2011a, p. 10).
Este es el comienzo de uno de sus más conocidos poemas, pero hagamos una breve, formal y moderna presentación. Daniel Bazán Lazarte nace en 1968 en la Ciudad de Buenos Aires. Actor, dramaturgo, y poeta. Cuenta con tres libros publicados ${ }^{6}$ y un disco de folklore ${ }^{7}$. Sus vínculos con la política son inescindibles -al menos en el relato- de su práctica artística $^{8}$. Destaca en su trayectoria artística su participación en "La Giribone", un "espacio de arte, militancia y resistencia cultural" que funcionó entre 2001 y 2009, y en el Asentamiento 8 de Mayo de José León Suárez". Dice haber "vuelto" a la militancia LGTB en relación a la campaña por la Ley del Matrimonio Igualitario, y luego por la Ley de Identidad de Género. Se reconoce parte de Futuro Trans, organización que edita la revista "El Teje", así como de la Asociación de Lucha por la Identidad Travesti (ALIT); todo un conjunto de pertenencias y amistades que pusieron a Daniel en contacto con "lo trans", un concepto de trans propuesto por Marlene Wayar $^{10}$, que sostiene que en tanto que trans, se es el primer objeto de arte por crear.
"[...] Susy nace como juego personal y artístico de Daniel Bazán Lazarte dentro de las Noches Bizarras ${ }^{11}$, pero fue legitimada y parida por las chicas de ALIT. [...]" (Pecoraro, 2010). Susy Shock es inicialmente un personaje que "[...] pasó a transitar mi vida cotidiana, mis vínculos. A través de ella encontré mi propia humanidad, o una síntesis que venía buscando. Desde Susy miro de otra manera." (Ortelli, 2013). Dos de sus libros y su disco, se reconocen como obra de Susy Shock, así como su ya clásico "Poemario trans-pirado", espectáculo que en 2014 fue distinguido por la Legislatura de la Ciudad Autónoma de Buenos Aires y declarado de interés para la promoción y defensa de los Derechos Humanos. Su producción, su colaboración y participación, son prolíficas: columnas en el suplemento SOY del Diario Página/12 y en la Revista MU de la cooperativa Lavaca; el ciclo radial Crianzas también producido por Lavaca; novela de folletín "La Loreta" en la Revista Maten al Mensajero; guion del cómic titulado "SuperShiva", ilustrado por Rubén Gauna en la Revista Clítoris; protagónico

6 Revuelo sur. Buenos Aires: Nuevos Tiempos, 2007, Trans Pirado. Buenos Aires: Nuevos Tiempos, 2011 y Relatos en Canecalón. Buenos Aires: Nuevos Tiempos, 2011.

7 "Buena vida y poca vergüenza", editado por UMI en 2014

$8 \quad$ "[...] Soy parte de la generación de toda la movida de los 80. Desde la política encaré la militancia en el arte [...]" (Pecoraro, 2010).

9 En este punto reconocemos como productivo para el análisis, el concepto de "activismo artístico", propuesto por Ana Longoni y Fernando Davis (2008) para referirse a "[...] producciones y acciones, muchas veces colectivas, que abrevan en recursos artísticos con la voluntad de tomar posición e incidir de alguna forma en el territorio de lo político".

10 Cabeza de la organización "Futuro Trans".

11 Espectáculo de varieté teatral realizado inicialmente en La Giribone, luego en Burlesque y que actualmente se realiza en La Oreja Negra con el nombre de "Las Noches Bizarras". 
en la película "Andrea. Un melodrama rioplatense", dirigida por Édgar De Santo. A todo lo que deben sumarse sus permanentes participaciones y presentaciones en espacios del under, acompañando a colectivos y artistas con su arte. En su vida personal, Susy Shock es padre/ madre de Anahí, hace casi ya 20 años, y mantiene hace diez lo que da por llamar "tri-pareja".

Nos interesa Susy Shock por estos cruces y solapamientos entre arte y militancia, y particularmente por el modo -quizás inevitable- de proponer un cuestionamiento constante del sujeto, en el que -también, inevitablemente- cae su propia figura. Susy Shock se reconoce a sí misma como "hecho artístico" y como parida por un colectivo sobre un escenario, cuyo límite, como dice "[...] se va haciendo $\tan$ finito [...]" (2011a, p. 10).

Que parió a Susy? - Un colectivo de gente, que fue Giribone (el lugar donde desplegó su arte) en el 2001. [...] un espacio que me permitió saltar del escenario a la cotidianidad de la gente, y desde ahí, a la calle. (MU, 2011).

Al principio de las Noches Bizarras, el personaje Susy era el de una travesti, [...] pero cuando empecé a profundizar en mí y empecé a juntarme con los movimientos travestis, fue mutando a un hecho político. Y el personaje dejó de serlo porque em- pezó a transitar zonas mías.” (Tauil, 2009).

Susy Shock se reconoce trans para, al mismo tiempo, desidentificarse de todo como "género colibrí", identificación estratégica y desidentificación:

Lo trans para mí es como un paraguas desde donde podemos enmarcarnos o desenmarcarnos en todo caso. Me gusta sentir que Susy va y no sabe hasta dónde. [...] tengo una construcción trans en mi propia vida personal, $[\ldots] \mathrm{Mi}$ vida personal, es trans." (Pecoraro, 2010).

"[...] Cuando me preguntan que soy, respondo: 'Soy género colibrí'. En realidad, es mi apuesta política, poética, de cómo quiero que me veas, de cómo quiero que hagas el esfuerzo para verme, porque me parece que si hay algo que estaría bueno es que hagamos el esfuerzo del reconocimiento al otro." (MU, 2011).

ser un ser sin género, sin necesidad de que un documento me confirme lo que soy. (SOY, 2013).

Todos estos extractos nos ponen sobre la vía de un proceso de singularización, de reapropiación de los componentes de la subjetividad a través de una relación de expresión y creación que se resiste a la integración y la normalización. Es destacable el hecho de que se reconozca como parida por un colecti- vo, lo cual permite abordar la relación entre la subjetividad como agenciamiento colectivo, el individuo como consumidor de subjetividad, y la singularización como proceso a la vez colectivo e individualmente encarnado. En su relato y en su obra, aparecen con claridad los tres niveles de los procesos de singularización en los que se frustra la interiorización de los valores dominantes del CMI:

A nivel infrapersonal, Susy no deja de insistir en la relación entre su pasado, su infancia, su presente y su esperanza de un futuro diferente:

Yo creo que siempre fui Susy aunque no sabía, porque tiene que ver con estar conectada con mis partes creativas. [...] desde niñita tuve la posibilidad de ser abrazada en eso que no sabía que iba a terminar siendo, y no sé si esto que soy ahora voy a terminar siendo, porque sigo jugando. (El tribuno, 2013).

Vivir creativamente es respetar al niño o niña que uno fue $\mathrm{y}$ aportar algo rico a la humanidad desde el espacio en que se esté. (Ortelli, 2013).

Qué pasaría si conseguimos una infancia y adolescencia donde se permita una evolución propia que no tenga que ver con estar ligada a sobrevivir y a la defensa frente a la violencia. Crecer en paz. ¿Qué sería cada uno si no tuvieran que estar huyendo 
del golpe, de la ignorancia, del ser expulsados, de qué comer hoy y modelos de feminidades y masculinidades? Yo qué sé que sería Susy si hubiese tenido mi generación la posibilidad de encontrar el modo de transitar nuestras sexualidades e identidades. Trato de ampliar las cosas para Anahí, mi hija, para los que van llegando. (Soy, 2013).

A nivel personal, insiste con respecto a su vida privada:

Mi deseo es deconstruirme, desarmar esas estructuras y ver con qué me encuentro [...] permitirse el deseo es la batalla contra el control. (Tauil, 2009).

La pelea indudablemente es contra los prejuicios que tenemos todos adentro, también dentro de nuestra comunidad LGTB (Pecoraro, 2010).

A nivel interpersonal, involucra formas de sociabilidad:

Yo cada vez creo menos en la amistad como ese concepto hasta capitalista de cofradía, prefiero la idea de los amores que vamos construyendo, sembrando, en las distintas etapas de nuestras vidas, si nosotrxs nos vamos renom- brando, reinventando, en esa propia creación de la que hablé al principio, así también nos pasa o nos debería pasar con los vínculos, con ese poder acompañarnos, amucharnos sin esas etiquetas, ese sumar amores grandes, chicos, medianos, redondos y multicolores sin esas únicas formas encapsuladas que nos traen en el supermercado del limpito vivir." (Revista Furias, 2012).

Lo micropolítico irrumpe en todo momento en cada uno de estos retazos de discurso, y despuntan permanentemente las estrategias de desidentificación e identificación estratégica, lo que permite reconocer un tipo de agenciamiento tendiente a evitar que la singularización sea reificada como identidad, potenciando los agenciamientos de unos con otros. En este proceso, no es menor lo que aporta a la experiencia de Susy Shock su relación con el movimiento militante travesti y particularmente con Marlene Wayar. La idea de "lo trans" como todo devenir posible, y de futuro transgenérico ${ }^{12}$, pueden pensarse como identificaciones estratégicas, tanto por ser en principio una identificación negativa, como por ser una identificación gueto o híper-identificación que se sostiene, en el fondo en una pretensión pos-identitaria: ser todo, seres sin género, no saber qué más podemos ser, "y que otros sean lo normal". Este tipo de estrategia resiste micropolíticamente a la serialización de la subjetividad buscando producir modos de subjetivación autónomos, generando su propia semiotización y cartografía. Son también estrategias sexopolíticas que movilizan los procesos de desterritorialización de la heterosexualidad con la transversalidad de sus devenires, que van de lo personal al movimiento, del cuerpo al espacio urbano, del colectivo al cuerpo individual.

La reivindicación "mi vida personal es trans", acompañada de su nacimiento en un colectivo en el contexto de producción cultural y festiva, permite que señalemos que lo que comenzó siendo un análisis de Susy Shock como sujeto, individual, ha terminado por ser una puerta de entrada a un conjunto de "políticas del ano". Se trata de un agenciamiento colectivo travesti, pero que no se queda en el gueto ${ }^{13}$, que disputa políticamente a partir de otro tipo de relaciones interpersonales, de la fiesta, de la autoexperimentación y el placer; términos que se repiten por todos lados en el discurso y la obra de los invo-

12 "Fui hétero, bi, gay... pero ahora me comprendo trans. Hay un futuro transgenérico donde todos somos todo, eso es lo que se viene". (Tauil, 2009).

13 "Una de las cosas más importantes que sucedió fue el hecho de colectivizar la diversidad que se generó a partir de las Noches Bizarras [...], donde estamos todas mezcladas, travas y heterosexuales. [...] Rompimos con esa manera de gueto de los boliches para travas, boliches para lesbianas, boliches para gays [...]. El arte es trans también y traspasa esos guetos y esos límites." (Pecoraro, 2010). 
lucrados. Susy Shock y todo lo que la rodea, hace evidente el modo en que la cultura puede ser un foro de creación en el que pueden definirse los límites de lo socialmente posible.

Ahora bien, además de todo este ensalzamiento de la "autocreación" como obra artística y todo lo potente de los devenires y lo molecular presentado hasta aquí, pueden identificarse también elementos autocríticos que permiten sostener que no se trata de voluntarismo individual, ni del devenir diferencial aislado en lo puramente artístico. Susy no es ingenua, y se reconoce como portadora de modelos. Podemos inferir que es consciente, a su modo, de su performance, de lo que pone en escena para "jugar, inquietar, dar nuevas formas", jugando con las normas del género de las cuales no puede sustraerse.

Yo qué sé qué sería Susy si hubiese tenido mi generación la posibilidad de encontrar el modo de transitar nuestras sexualidades e identidades. [...] Pero sé que yo no dejo de estar repleta de modelos, porque también soy de lo que voy pudiendo ser. (Soy, 2013).

También pasa por convertir, que ser trava no sea simplemente la reproducción de los mandatos femeninos que ya la mujer no quiere tener más $[\ldots]$. Las chicas trans, $[\ldots]$ quieren entrar en eso, cuando hace rato que la mayoría de las mujeres quieren salir. (Pecoraro, 2010).

Podemos también reconocer su compromiso con las "luchas de interés" en su participación en las campañas por la Ley del matrimonio igualitario y de identidad de género y "los reclamos y las luchas específicas que se armaron a través de "El teje" (Pecoraro, 2010). Su testimonio deja muy en claro la relación que establece entre las revoluciones moleculares y las luchas de interés.

Pienso en lo que me trajo hasta acá: ser un ser sin género, sin necesidad de que un documento me confirme lo que soy, pero saber que a su vez un documento puede garantizar la felicidad de las personas que amo. (Soy, 2013).

Quiero jugar. Jugar es inquietar, agarrar la masilla y dar nuevas formas. Creo que está faltando un diálogo más profundo con las organizaciones. Muchas veces la gente te ubica en el moño del regalo, como que el arte está a disposición y es un adorno. No se está entendiendo que somos parte, o que somos vehículo vital, en el discurso político, no reconocen el poder de convocatoria que le damos a la mesa de debate. Pienso que no estamos pensando tácticas nuevas como militancia [...]. Salieron leyes importantísimas, es el momento de que la militancia pegue un vuelco creativo. (Soy, 2013).

Desde el punto de vista del machismo reinante en nuestra sociedad tan patriarcal y tan desigual, [...] la ley de identidad de género [...] es ni más ni menos que poderse soñar un futuro en un Estado de Derecho que hasta ahora no solo había sido ajeno a esos y otros reclamos, sino que inclusive ha puesto su aparato represivo en contra de nosotros como minoría, sumado a una ley de avanzada, pensada y peleada además por el mismo colectivo. En cuanto al matrimonio, personalmente no es una institución en la que crea, he apoyado pero críticamente para dar ese debate, sobre todo por lxs contrincantes muy fachos y tan poderosxs que se tenía en frente, como las iglesias, pero soy más de la idea de proponer esos otros modos de vínculos amorosos que los géneros y las sexualidades divergentes podemos aportar para tantxs otrxs, que además nos viven demostrando a diario que las instituciones como ésa, no solo están caducas sino que no hacen muy feliz a la gente. (Revista Furias, 2012).

El cambio es cultural, hay leyes muy poderosas logradas hace muy poco que son avances enormes. [...] hacer efectivo eso nos tomará tantos años más. Cuando veamos periodistas travestis, o trans ejerciendo la docencia, estaríamos hablando de eso. Hay 
tímidos casos actualmente, que tienen que ver con la insistencia de la militancia. Son casos de gente que ha expuesto su propia vida en pos de abrir ese camino. (El tribuno, 2013).

Estos últimos dos extractos nos permiten también señalar el poder de la homosexualidad como devenir capaz de recodificar los flujos de saber poder dando lugar a nuevas formas de conocimiento, punto en el que la relación entre teoría y militancia dan voz a los sujetos abyectos para producir su propio saber, para reapropiarse de las tecnologías de poder.

\section{Preguntas trans-versales}

En vez de seguir distrayéndonos con nuestras pequeñas luchas identitarias, pensemos cuáles son las técnicas de producción de la vida con las que nos queremos construir colectivamente. La identidad al final es otra de las ficciones de las que se sirve el neoliberalismo para evitar que podamos llevar a cabo una lucha global.

-Paul/Beatriz Preciado

Volvamos entonces a las preguntas iniciales: con un sujeto concebido como producto de agenciamientos y dispositivos, ¿quién y cómo pueden disputar el campo social? ¿qué valor tienen las experiencias subjetivas individuales? ¿dónde quedan y cómo existen los cuerpos dota- dos de conciencia que soportan y forman parte de esos agenciamientos y dispositivos? Respondamos primero con la voz del colibrí:

Hay artistas que exceden el hecho artístico y empiezan a connotar las riquezas de un entramado social muy poderoso (El tribuno, 2013).

Susy es una síntesis de todo lo ideológico que me rodea. (Pecoraro, 2010).

Más que una avanzada mía, el tema es un clima general, en el que Susy tenía que estar. (Pecoraro, 2010).

Susy Shock [...] es el resultado de lo mejor y lo peor que tenemos como sociedad (Tauil, 2009).

El ejercicio de indagar en el problema del sujeto del cambio social en el posestructuralismo, nos ha puesto constantemente en el límite entre lo social y lo individual, entre agencia y estructura, trayendo al centro de la discusión el carácter político de todo aquello que podríamos haber considerado personal. Encontramos que "el sujeto", en tanto que ya no es pensado desde los supuestos cartesianos, no remite en los autores recorridos a una unidad, ni siquiera a una unidad abierta, en proceso, agujereada. El sujeto político aparece como inevitablemente plural y procesual. Lo que interesa son los procesos de subjetivación en tanto que agencia- mientos colectivos, conjunto de dispositivos, discursos, prácticas, que son inevitablemente sociales. El problema político no es que haya o no individuos, sino el modo en que lo extra y lo infra personal se agencian, y el modo en que equipamientos colectivos como el lenguaje urden tramas de sentido, haciendo posible una subjetividad hegemónica que se hará luego presa de los cuerpos y de los individuos como terminales consumidoras de subjetividad por medio de dispositivos pedagógicos y normalizadores.

Sistemas económicos, tecnológicos, icónicos, ecológicos, mediáticos, sistemas de percepción, sensibilidad, afecto, deseo, representación, biológicos, fisiológicos, entre tantos más, son agenciados, puestos en relación de producción maquínica, encrucijada de múltiples componentes de la subjetividad de la que el individuo emerge. La subjetividad es producida en y por todo ese conjunto de órganos y dispositivos, podría incluso pensarse como un "clima de época" en el que el individuo es posible, y lo dice Guattari (2006) con claridad, "en lugar de ideología prefiero hablar siempre de subjetivación" (p. 39). Así entendida la subjetividad, cuando se pone la atención sobre los devenires diferenciales, aquellos que atraviesan transversalmente los distintos niveles y agenciamientos, es que queda expuesto el modo 
en que se articulan o agencian el nivel molecular subjetivo, la producción de un inconsciente, con el nivel molar de los problemas políticos y sociales entendidos en términos más generales, lo cual disuelve el problema del sujeto en lo social. De aquí la centralidad otorgada al movimiento o las multitudes queer en la disputa política. Es en el registro del agenciamiento colectivo que pueden disputarse los límites, las normas, las relaciones, en otras palabras, la axiomática de la subjetividad dominante y su lenguaje, que es también un agenciamiento colectivo.

Si los modos de producción de subjetividad en el CMI trabajan como modos de producción de un saber-poder sobre la vida, es allí donde debe darse la disputa, buscando dar lugar a agenciamientos desviados que disputen tanto el sujeto de la enunciación del saber, como los modos de producción de la vida: desatar procesos de singularización en lugar de procesos identitarios. Esto no debe comprenderse como modos de construcción de individuos particulares, sino de modos de construcción de agenciamientos colectivos, capaces de ofrecer una subjetividad no excluyente, en relación a la cual los individuos puedan constituirse, no por identificación y normalización, sino por automodelación, manteniendo una relación de expresión y creación con la subjetividad, reapropiándose de sus elementos.

Se entiende entonces que las multitudes queer, la sexopolítica, y los movimientos en general, sean sostenidos como las formaciones capaces de sostener esta lucha, que no puede darse al nivel del individuo, o partiendo de un sujeto moderno de tipo cartesiano. Por ello es que Susy Shock solo puede entenderse como posible en el entramado de un conjunto de elementos extra e infra personales. Su caso nos ofrece la particularidad de ser una individualidad "fuerte", reconocida, con cierta "fama", pero que al intentar conocerla se diluye en todo el conjunto de relaciones que constituye y que la constituyen. Susy Shock es parte de un proceso de singularización sostenido por un colectivo en el registro de la militancia cultural y artística. Susy Shock, a fin de cuentas, puede ser pensada como un individuo consumidor de una subjetividad que no puede, de ninguna manera, sustraerse de la subjetividad hegemónica, pero que puede reconocerse como una subjetividad disidente, que da claras cuentas de un agenciamiento procesual con una posición ofensiva, concentrada en movilizar devenires, tal como aparece en las metáforas del juego, la exploración, el descubrimiento.

Se hace así necesario poder indagar justamente en lo multitudinario, en lo colectivo, en el proceso de subjetivación y singularización en sí mismo del que Susy es producto-agente; asumiendo que quizás ya no tenga mucho sentido pensar quién está haciendo la revolución, sino cómo se deviene, se fuga en tanto que individualidad, pero solo como parte de un agenciamiento en sí mismo en fuga.

Lo que pasa es que no tiene que ser un camino solitario, tiene que ser colectivo. Yo no siento que sea un camino individual, y si lo es me parece acotado, porque queda ahí como una propuesta puntual y única, de alguien, sin que pase más. [...] me parece que hay que apostar a ese camino, a ese fluir. Porque, si no somos siempre resonancia de defensas. Yo estoy llena de construcciones de ese tipo, porque es mi generación, defendiéndome del otro, a pesar del otro. Y a mí me gustaría que la pendejada venga y pueda fluir. Mi generación viene resistiendo ser y no está pudiendo fluir. La pregunta sería, entonces: ¿Cómo fluir en ese ser sin necesidad de que sea siempre una reacción contra algo? Tendremos que ir por esa respuesta. (Rosales Zeiger, 2013). 


\section{Referencias}

Ávila Rodríguez, A. (enero-junio de 2014). De la germinación de lo siniestro: La belleza en espejo roto. La Palabra, (24), 99-106.

Bejarano Hernández, A. (enero-junio de 2017). Palimpsestos con Hélène Cixous: experimentos consigo mismo.La Palabra, (30).

Butler, J. (2002). Críticamente subversiva. En Sexualidades Transgresoras. Una antología de estudios queer (pp. 55-79). Barcelona: Editorial Icaria.

Butler, J. (2007). El género en disputa. El feminismo y la subversión de la identidad. Barcelona: Paidós.

Chico Quintana, R. (julio - diciembre de 2014). La formación de la identidad abyecta como una respuesta ética de contracultura. La Palabra (25), 107-126.

Deleuze, G., \& Guattari, F. (2002). Mil Mesetas. Capitalismo y esquizofrenia. España: Pre - Textos.

El Tribuno. (2013, 06 de enero). Lo mediocre de este mundo tiene que ver con no ser creativos. El tribuno. Recuperado de http://www.eltribuno.info/lo-mediocre-este-mundo-tiene-que-ver-no-sercreativos-n240202

Fernández de Rota Irimia, A. (2008). Movimientos sociales. Una lectura a partir del postestructuralismo. Athenea Digital, (14), 63-81.

Foucault, M. (2002). Defender la sociedad. Curso en el Collège de France (1975-1976) (H. Pons, trad.). Buenos Aires: FCE.

Guattari, F. (2004). Plan sobre el planeta. Capitalismo mundial integrado y revoluciones moleculares. Madrid: Traficante de sueños.

Hardt, M., \& Negri, A. (2002). Imperio. Buenos Aires: Paidós.

Hernández Peñaloza, A.A. (enero-junio de 2016). El diario de un escritor en Encuentro en Saint-Nazaire de Ricardo Piglia. La Palabra, (28), 75-90.

Longoni, A., \& Davis, F. (2008). Las vanguardias, neovanguardias, posvanguardias: cartografías de un debate. Katakay, 5(7), 6-11.

MU. (2011). Teoría (y práctica) del shock. MU, 5(44), 22-23.

Noguera, J. (2003). El neoestructuralismo sociológico. En S. Giner (coord.), Teoría sociológica moderna.[AdJME1] Madrid: Editorial Ariel.

Ortelli, M. (2013, 23 de junio). Transpirando la camiseta. Página/12. Recuperado de http://www.pagina12.com.ar/diario/suplementos/radar/9-8934-2013-06-29.html 
Pecoraro, G. (2010). Susy Shock, trans pirada. SentidoG.com. Recuperado de http://www.sentidog.com/ lat/2010/10/susy-shock-trans-pirada.html

Pinzón Manrique, H. J. (enero-junio de 2014). La literatura como in-corporación: el cuerpo como proceso. La Palabra, (24), 91-97.

Preciado, B. (2003). Multitudes Queer: notas de una política para "los anormales”. Multitudes, (12). París: Editorial Exils.

Preciado, B. (2009). Terror Anal. En El deseo homosexual (pp. 133-170). España: Editorial Melusina.

Revista Furias. (2012). No hay Susy sin arte. Plantita seca sería. Revista Furias, (14). Recuperado de http://revistafurias.com/entrevista-a-susy-shock/

Rolnik, S., \& Guattari, F. (2006). Micropolítica. Cartografias del deseo. Madrid: Traficantes de Sueños.

Rosales Zeiger, C. (2013, 29 de diciembre). A veces le falta sentido del humor y sentido de juego a la militancia. Diálogo con Susy Shock. Andén, (76). Recuperado de http://andendigital.com.ar/ dialogos/754-susyshok76

Soy. (2013, 14 de junio). El colibrí canta hasta morir. SOY. Recuperado de http://www.pagina12.com. ar/diario/suplementos/soy/1-2973-2013-06-14.html

http://www.pagina12.com.ar/diario/suplementos/soy/1-2973-2013-06-14.html

Shock, S. (2007). SUSY SHOCK “¿Qué soy?...” [Entrada en blog]. Susy Shock. Recuperado de: http:// susyshock.blogspot.com/2007/09/susy-shock-qu-soy.html

Shock, S. (2011a). Poemario Trans Pirado. Buenos Aires: Nuevos tiempos.

Shock, S. (2011b). Relatos en canecalón. Buenos Aires: Nuevos tiempos.

Shock, S. (2014). Buena vida y poca vergüenza [CD ROM]. Buenos Aires: UMI.

Shock, S. (2016). Crianzas. Historias para crecer en toda la diversidad. Buenos Aires: muchas nueces.

Shock, S. (2017). Hojarascas. Buenos Aires: muchas nueces. Tauil, J. (2009, 09 de enero). Bizarra noche y día. SOY. Recuperado de http://www.pagina12.com.ar/diario/suplementos/soy/1-533-200901-09.html

Tonkonoff, S. (2009). Sujeción, Sujeto, Autonomía. Notas sobre una Encrucijada Actual. Ciudadanía y Autonomía. México: UNAM.

Vargas Quiroz, A. P. (julio - diciembre de 2014). Me gustan tus ojos miopes (o del diálogo con Hélène Cixous para llevar al cuerpo, a la literatura, a la vida). La Palabra (25), 143-156. 